\title{
Mild and Chemoselective Phosphorylation of Alcohols Using a $\Psi$-Reagent
}

Michał Ociepa, ${ }^{1}$ Kyle W. Knouse, ${ }^{1}$ David He,${ }^{1}$ Julien C. Vantourout, ${ }^{1}$ Dillon T. Flood, ${ }^{1}$ Natalia M. Padial, ${ }^{1}$ Jason S. Chen, ${ }^{2}$ Brittany B. Sanchez, ${ }^{2}$ Emily J. Sturgell, ${ }^{2}$ Bin Zheng, ${ }^{3}$ Shenjie Qiu, ${ }^{3}$ Michael A. Schmidt, ${ }^{3}$ Martin D. Eastgate, ${ }^{3}$ Phil S. Baran ${ }^{1 *}$

${ }^{1}$ Department of Chemistry, Scripps Research, 10550 North Torrey Pines Road, La Jolla, California, 92037, United States
${ }^{2}$ Automated Synthesis Facility, Scripps Research, 10550 North Torrey Pines Road, La Jolla, California, 92037, United States
${ }^{3}$ Chemical Process Development, Bristol Myers Squibb, One Squibb Drive, New Brunswick, New Jersey, 08901, United States

\begin{abstract}
An operationally simple, scalable, and chemoselective method for the direct phosphorylation of alcohols using a $P(V)$-approach based on the $\Psi$-reagent platform is disclosed. The method features a broad substrate scope of utility in both simple and complex settings and provides access to valuable phosphorylated alcohols that would be otherwise difficult to access.
\end{abstract}

Main text. Phosphorylation of alcohol-containing biomolecules is one of Nature's most simple methods for regulating cell circuitry. ${ }^{1}$ Introduction of a phosphate group can also be critical in the medicinal, ${ }^{2}$ agrochemical, ${ }^{3}$ and materials areas. ${ }^{4}$ Biological enzymatic phosphorylation overcomes thermodynamic barriers to achieve selective functionalization through molecular recognition and by lowering the activation energy of the $\mathrm{P}-\mathrm{O}$ bond forming step. ${ }^{5}$ Current purely chemical alcohol phosphorylation methods all suffer from various limitations and/or multistep processes (Figure 1) ${ }^{6-10}$ For example, the use of P(III)-based phosphoramidites require a three step process for installation including protecting group removal and oxidation. ${ }^{7} \mathrm{P}(\mathrm{V})$ based strategies such as the use of $\mathrm{POCl}_{3}$ and derivatives thereof can be problematic due to over reactivity (often producing mixtures of mono-, di-, and tri-alkylphosphates) and protecting group manipulations. ${ }^{8}$ The direct use of phosphoric acid requires high temperatures and exhibits limited scope due to the high acidity and harsh conditions. ${ }^{9}$ Activation methods used in concert with phosphoric acid or its salts have been employed with limited scope. ${ }^{10}$ The recently reported bioinspired method based on an enzymatically produced $\mathrm{P}(\mathrm{V})$-reagent (PEP-K) solves many of these problems despite requiring its use in excess at 100 ${ }^{\circ} \mathrm{C} .{ }^{11}$ However, like all known methods it suffers from a lack of chemoselectivity (in this case free amines are not tolerated). The recently disclosed $\mathrm{P}(\mathrm{V})$-based $\Psi$-platform for the construction of P-linkages has been applied to the simplified synthesis of an ever growing, diverse range of compounds such as: cyclic dinucleotides, ${ }^{12,13}$ stereopure anti-sense oligonucleotides, ${ }^{12}$ methylphosphonates, ${ }^{14}$ chiral phosphines, ${ }^{14}$ DNA $^{5}$ and protein bioconjugates, ${ }^{16}$ complex alkaloids, ${ }^{17}$ and fully chemically modified oligonucleotides using a commercial automated synthesizer. ${ }^{18}$ As part of the ongoing $\Psi$-platform development, $\Psi^{\mathrm{O}}(\mathbf{1})$ was identified as a suitable reagent for forging phosphodiester bonds. ${ }^{18}$ This Letter builds on those findings to highlight how the chemoselective nature of $\Psi$-reagents can be leveraged to access phosphates from alcohols in a mild, scalable, and operationally simple (one-pot) fashion across a wide range of alcohol substrates.

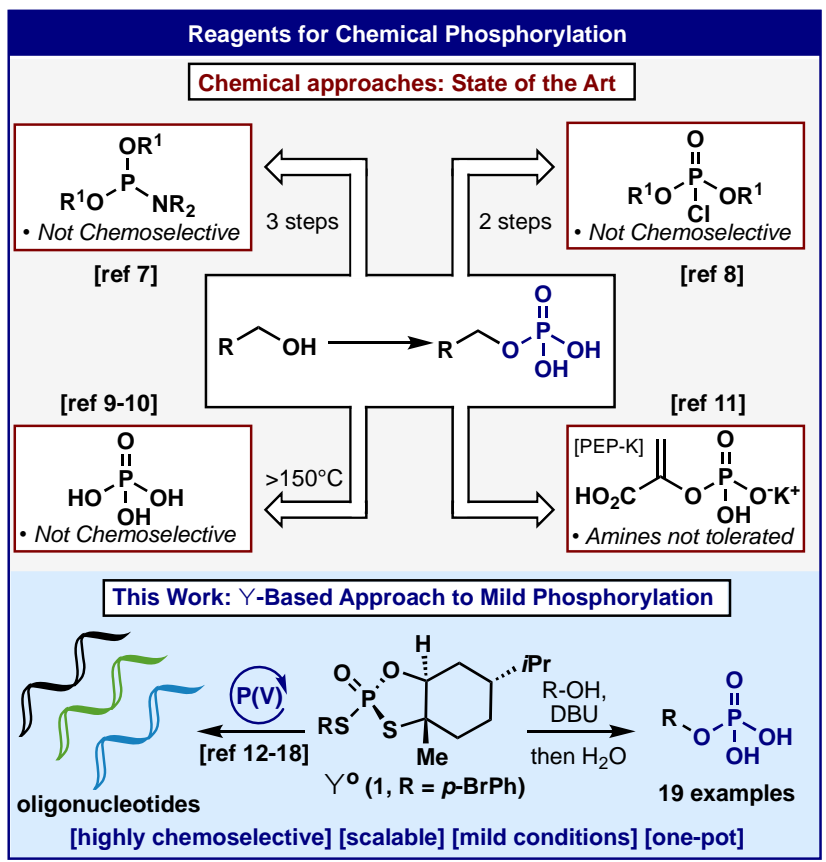

FIGURE 1. Alcohol phosphorylation: Literature precedent, limitations, and a mild solution using the $\Psi^{\mathrm{O}}$ reagent (1).

Previous work on the $\Psi$-platform demonstrated that these reagents facilitate formation of phosphate (or thiophosphate) linkages via stepwise nucleophilic addition of two different alcohols. ${ }^{12}$ In a similar manner, appendage of an alcohol to the $\Psi^{\mathrm{O}}$ reagent to form intermediate $\Psi$-loaded adduct, followed by addition of water should in principle lead to the formation of monoalkyl phosphate. To explore the feasibility of this idea, alcohol $\mathbf{2}$ was chosen as a simple substrate to start optimization efforts (Table 1A). In fully optimized form, the reaction requires 1.5 equivalents of $\Psi^{\mathrm{O}}$ and DBU as lower quantities lead to diminished yield due to 
formation of double addition products (dialkylphosphates, Table 1A, entry 2) or decreased conversion (Table 1A, entry 3). Consistent with prior findings, the reaction performs best with DBU as a base although DBN and DABCO furnish product in diminished yield (Table 1A, entries 4-8). Best conversions are achieved in anhydrous DCM although $\mathrm{MeCN}$ or DMF can be used with only slightly lower yields (Table 1A, entries 9-12). Unsurprisingly, control experiments confirm the need for $\Psi^{\mathrm{O}}$ and base for initial $\mathrm{P}-$ $\mathrm{O}$ bond formation, and $\mathrm{H}_{2} \mathrm{O}$ for the hydrolysis step (Table 1A, entries 13-15). The reaction can be performed without using anhydrous solvent and open to air, but affords the desired product with diminished yield due to competing hydrolysis of $\Psi^{\circ}$ reagent during loading step (Table 1A, entries 16 and 17).

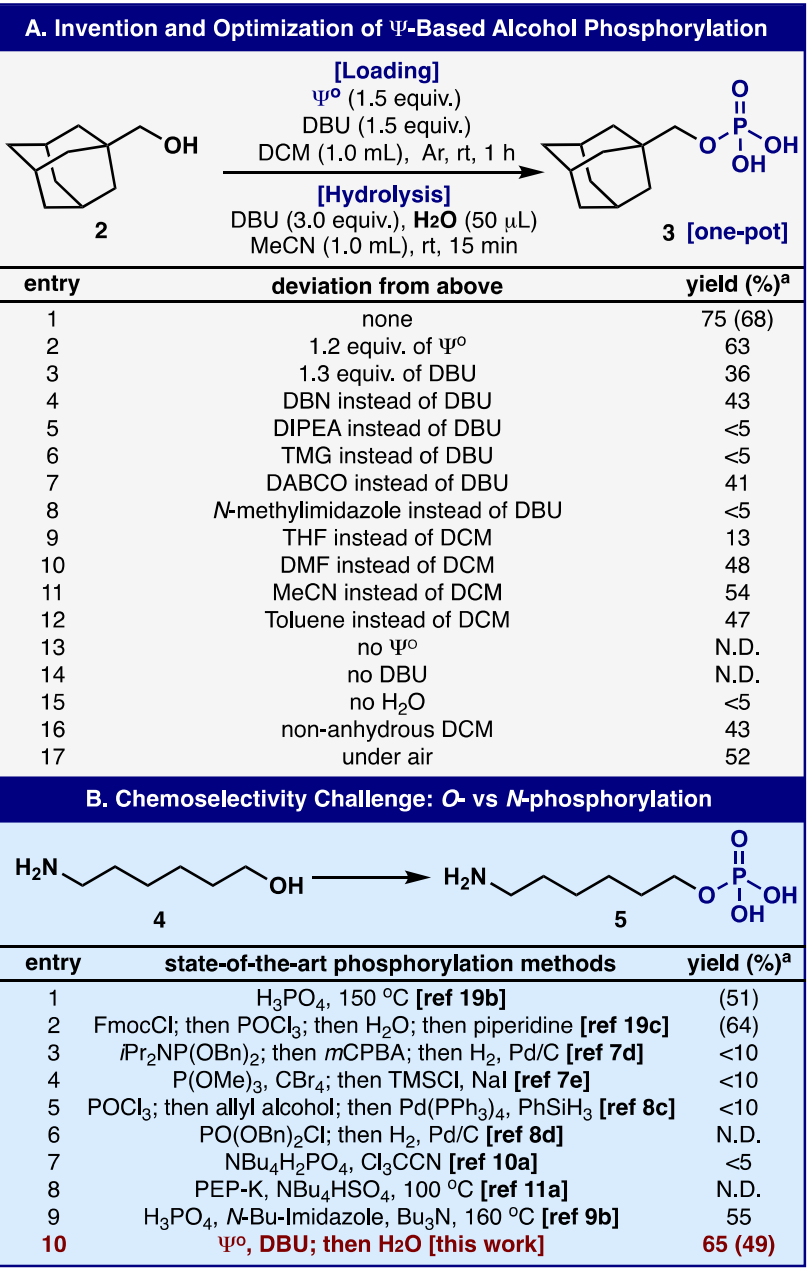

TABLE 1. (A) Optimization of $\Psi$-based alcohol phosphorylation and (B) its use in the selective $O$-phosphorylation of aminoalcohol 4. ${ }^{\text {a }}$ Yields determined by quantitative ${ }^{31} \mathrm{P}$ NMR (see SI). Isolated yields in brackets.

$\varpi$-Aminoalkyl dihydrogen phosphates and their salts are used as active ingredients in cosmetics, promoting fibroblast proliferation and collagen biosynthesis. ${ }^{19}$ They are also employed in biochemistry as linkers for bioconjugates. ${ }^{20}$ However, their availability is hampered by inconvenient synthetic routes. For instance, compound $\mathbf{5}$ was previously synthesized in $51 \%$ isolated yield (only melting point and elemental analysis reported) by condensation with crystalline $\mathrm{H}_{3} \mathrm{PO}_{4}$ at $150{ }^{\circ} \mathrm{C}$ under high vacuum (Table 1B, entry 1). ${ }^{20 \mathrm{~b}}$ Milder routes to phosphate 5 require Fmocprotection of the amine functionality, followed by phosphorylation by $\mathrm{POCl}_{3}$, and deprotection (64\% over 3 steps, entry 2). ${ }^{20 \mathrm{c}}$ As it is known that $\Psi$ reagents are exquisitely $O$-selective, ${ }^{16}$ the chemoselectivity of the direct phosphorylation in the context of $\varpi$-aminoalcohol $\mathbf{4}$ was examined. We started by surveying 7 literature conditions and out of those reported protocols, six delivered little to no observable 5 with the main byproduct being both $N$ - and $O$ phosphorylation as part of a complex mixture (Table 1B, entries 3-8). Only the harsh conditions of phosphoric acid at $160{ }^{\circ} \mathrm{C}$ delivered synthetically useful yields in our hands (entry 9) likely due to the in situ protonation of the amine. In stark contrast, our newly developed conditions using $\mathbf{1}$ followed by hydrolysis cleanly provided $\mathbf{5}$ at ambient temperature (Table 1B, entry 10). Importantly, no $N$ phosphorylated product could be observed by ${ }^{31} \mathrm{P}$ NMR.

The scope of this method was exemplified by the preparation of 19 different phosphorylated alcohols (Table 2). It is worth noting that, most of the older papers in this field present only analysis based on melting point and elemental analysis (occasionally ${ }^{31} \mathrm{P}$ NMR). More recent disclosures, with very few notable exceptions, ${ }^{8 c, 9 c, 10 a, 11}$ usually do not include high resolution images of NMR spectra. It is also common that such methodology papers report only conversions not isolated yields, presumably due to the difficulty in handling those polar substances. To be sure, multiple methods have been reported for the purification of phosphates including: HPLC, ${ }^{11 a}$ HILIC, ${ }^{10 a}$ solid phase ion exchange, ${ }^{9 c, 10 \mathrm{a}}$ and recrystallization. ${ }^{10 \mathrm{~b}} \mathrm{We}$ found that in small scale experiments HPLC was superior (see SI for column and eluent conditions) whereas HILIC was the method of choice for larger scale preparations or for compounds that are extremely polar. In some cases, it was convenient to isolate phosphates as their ammonium salts. As indicated in Table 2A, simple amines are tolerated in this reaction $(\mathbf{5}, \mathbf{1 4}, \mathbf{1 5})$ as well as basic heterocycles $(\mathbf{1 6}, \mathbf{1 9})$. Alkynes (7), azides (8), thiophenes (9), aryl iodides (10), olefins $(\mathbf{1 1})$, alkyl halides $(\mathbf{1 2}, \mathbf{1 3})$, nitro arenes $(\mathbf{1 7}, \mathbf{1 9})$, and indoline (18) were unscathed upon P-O bond formation. Finally, four medicinally relevant substrates were phosphorylated (Table 2B): metronidazole (19), AZT (20), cholesterol (21), and a tyrosine-containing peptide bearing histidine, aspartamide, and glutamide side-chains. Prior routes to some of these compounds were either laborious or contained limited experimental data such as the preparation of 7 (three steps $^{21}$ utility in biomolecule functionalization), ${ }^{22} \mathbf{1 4}$ (three steps), ${ }^{23} \mathbf{2 0}$ (most methods 


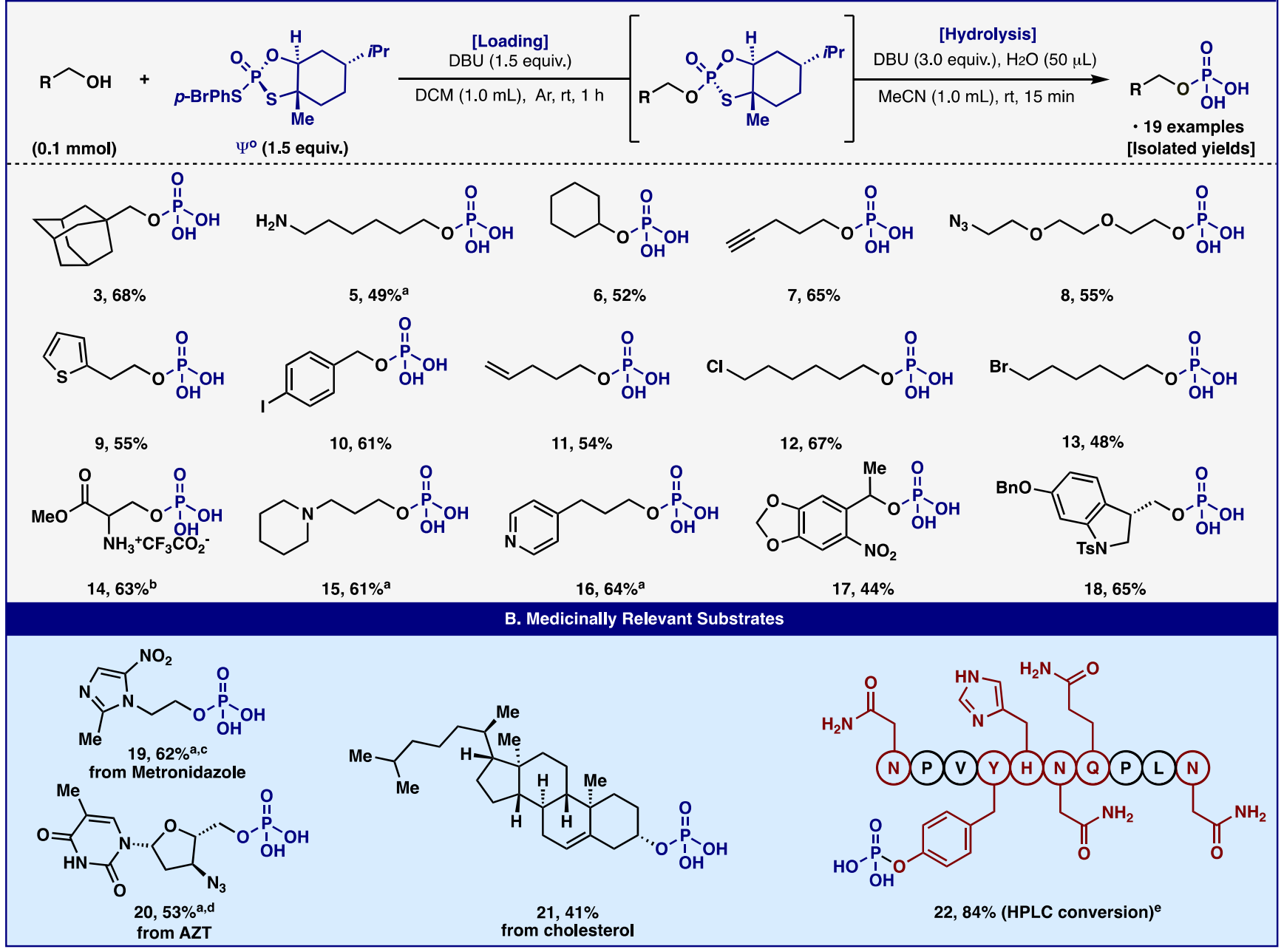

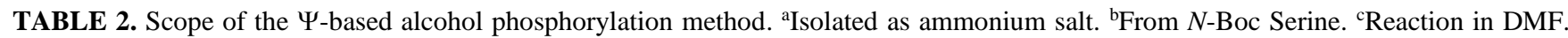
${ }^{\mathrm{d}}$ Reaction in MeCN. ${ }^{\mathrm{e}} \Psi^{\mathrm{O}}$ (5.0 equiv.), DBU (5.0 equiv.), reaction in DMF on a $1.0 \mu \mathrm{mol}$ scale.

$<35 \%$ yield $^{24 a}$ or multistep procedures ${ }^{24 b, c}$ with one paper showing higher yield with $\mathrm{POCl}_{3}$ and characterization based only on UV spectrum; ${ }^{24 d}$ enhanced HIV1 activity reported $^{25}$ ), and $\mathbf{2 1}$ (one ${ }^{10 c}$ and three ${ }^{26}$ step routes given with little characterization data). The limitations of this reaction (see SI for details) stem from lack of tolerance of preexisting functionality on the alcohol to basic conditions, and lower nucleophilicity of sterically hindered substrates (i.e. tertiary alcohols).

The intermediate $\Psi$-loaded adducts can also be used for the preparation of dialkyl phosphates rather than free phosphates. As shown in Figure 2, alcohol 2 could be loaded with reagent 1 followed by addition of $\mathrm{BnOH}$ to deliver dialkyl phosphate $\mathbf{2 3}$ in $42 \%$ isolated yield (without any additional optimization). The scalability of this reaction was also demonstrated using metronidazole wherein the standard protocol ( $0.1 \mathrm{mmol}$ scale) could be increased 30 -fold while maintaining efficiency.

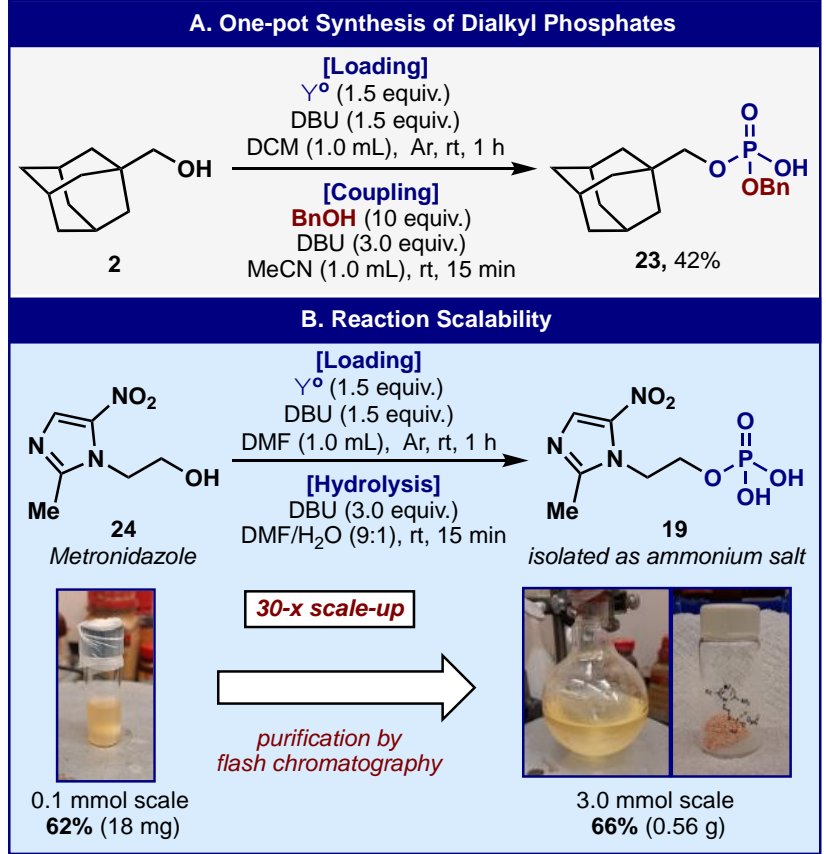

FIGURE 2. (A) One-pot synthesis of dialkyl phosphate 23 and (B) scale up of $\Psi$-based phosphorylation of metronidazole. 
The operationally simple phosphorylation method described herein represents a useful addition to the toolkit for installing this important functional group in a chemoselective fashion and is yet another example of the versatility of the $\Psi$-platform in organic synthesis.

\section{AUTHOR INFORMATION}

\section{Corresponding Author}

Phil S. Baran - Department of Chemistry, Scripps Research, La Jolla, California, 92037, United State; orcid.org/0000-0001-91939053; Email: pbaran@scripps.edu

\section{Present Addresses}

Kyle W. Knouse - Elsie Biotechnologies, 4955 Directors Place, San Diego, California, 92121, United States

Julien C. Vantourout - Univ Lyon, Université Lyon 1, CNRS, INSA, CPE-Lyon, ICBMS, UMR 5246, 69622 Villeurbanne, France

Dillon T. Flood - Elsie Biotechnologies, 4955 Directors Place, San Diego, California, 92121, United States

Natalia M. Padial, Instituto de Ciencia Molecular (ICMol), Universitat de València, 46980 València, Spain

Bin Zheng - Bristol Myers Squibb, 1 Squibb Dr. New Brunswick, New Jersey, 08903, United States

Shenjie Qiu - Bristol Myers Squibb, 1 Squibb Dr. New Brunswick, New Jersey, 08903, United States

Michael A. Schmidt - Bristol Myers Squibb, 1 Squibb Dr. New Brunswick, New Jersey, 08903, United States

Martin D. Eastgate - Bristol Myers Squibb, 1 Squibb Dr. New Brunswick, New Jersey, 08903, United States

\section{Author Contributions}

The manuscript was written through contributions of all authors. All authors have given approval to the final version of the manuscript.

\section{ACKNOWLEDGMENT}

Financial support for this work was provided by Bristol-Myers Squibb and NIGMS (GM-118176). M. O. was supported by the Polish National Agency for Academic Exchange (the Bekker programme no. PPN/BEK/2020/1/00111/DEC/1). N. M. P. thanks the European Union for a Marie Skłodowska-Curie Global Fellowship (H2020-MSCA-IF-2016-GF-749359-EnanSET) and Ia Caixa Foundation for the 2020 Post-doctoral Junior LeaderRetaining Fellowship (ID 100010434 LCF/BQ/PR20/11770014). We thank Dr. D.-H. Huang and Dr. L. Pasternack (Scripps Research) for NMR spectroscopic assistance.

\section{REFERENCES}

1. (a) Hunter, T. Why nature chose phosphate to modify proteins. Phil. Trans. R. Soc. B 2012, 367, 2513-2516. (b) Johnson, L. N.; Lewis, R. J. Structural Basis for Control by Phosphorylation. Chem Rev. 2001, 101, 2209-2242. (c) Berridge, M. J.; Irvine, R. F. Inositol phosphates and cell signalling. Nature 1989, 341, 197-205. (d) Olsen, J. V.; Blagoev, B.; Gnad, F.; Macek, B.; Kumar, C.; Mortensen, P.; Mann, M. Global, In Vivo, and Site-Specific Phosphorylation Dynamics in Signaling Networks. Cell 2006, 127, 635-648.

2. (a) Schultz, C. Prodrugs of Biologically Active Phosphate Esters. Bioorg. Med. Chem. 2003, 11, 885-898. (b) Pradere, U.; Garnier-Amblard, E. C.; Coats, S. J.; Amblard, F.; Schinazi, R. F. Synthesis of Nucleoside Phosphate and Phosphonate
Prodrugs. Chem. Rev. 2014, 114, 9154-9218. (c) Yao, C.; Wei C.; Huang, Z.; Lu, Y.; El-Toni, A. M.; Ju, D.; Zhang, X.; Wang, W.; Zhang, F. Phosphorylated Peptide Functionalization of Lanthanide Upconversion Nanoparticles for Tuning Nanomaterial-Cell Interactions. ACS Appl. Mater. Interfaces 2016, 8, 6935-6943. (d) Ramaswamy, J.; Nam, H. K.; Ramaraju, H.; Hatch, N. E.; Kohn, D. H. Inhibition of osteoblast mineralization by phosphorylated phage-derived apatite-specific peptide. Biomaterials 2015, 73, 120-130.

3. Phosphorus. An Outline of its Chemistry, Biochemistry and Technology $4^{\text {th }}$ Ed.; Corbridge D. E. C., Ed.; Elsevier, 1990, pp. 495-554.

4. Bhat, G. A.; Kalita, A. Ch.; Murugavel, R. Intriguing structural chemistry of neutral and anionic layered monoalkylphosphates: single-source precursors for high-yield ceramic phosphates. CrystEngComm 2017, 19, 5390-5401.

5. Lassila, J. K.; Zalatan, J. G.; Herschlag, D. Biological Phosphoryl-Transfer Reactions: Understanding Mechanism and Catalysis. Annu. Rev. Biochem. 2011, 80, 669-702.

6. Fiore, M. The synthesis of mono-alkyl phosphates and their derivatves: an overview of their nature, preparation and use, including synthesis under plausible prebiotic conditions. Org. Biomol. Chem. 2018, 16, 3068-3086.

7. For selected examples of P(III)-based phosphorylation see: (a) Perich J. W.; Johns, R. B. A New, Convenient and Efficient General Procedure for the Conversion of Alcohols into Their Dibenzyl Phosphorotriesters using $N, N$-Diethyl Dibenzyl Phosphoramidite. Tetrahedron Lett. 1987, 28, 101-102. (b) Jordan, P. A.; Kayser-Bricker, K.-J.; Miller, S. J. Asymmetric phosphorylation through catalytic $\mathrm{P}(\mathrm{III})$ phosphoramidite transfer: Enantioselective synthesis of D-myo-inositol-6phosphate. PNAS 2010, 107, 20620-20624. (c) Ross, K. C.; Rathbone D. L.; Thomson, W. Freeman, S. Use of Bis[2(trialkylsilyl)ethyl] $N, N$-Dialkylphosphoramidites for the Synthesis of Phosphate Monoesters, J. Chem Soc. Perkin Trans. 1 1995, 421-426. (d) Guo, C.; Dagostino, E. F.; Dong, L.; Hou, X.; Margosiak, S. A. Phosphate/Sulfate Ester Compounds and Pharmaceutical Compositions for Inhibiting Protein Interacting NIMA (PIN1). 2004, Patent no. WO2004087720. (e) Oza, V. B.; Corcoran, R. C.; A Mild Preparation of Protected Phosphate Esters from Alcohols. $J$. Org. Chem. 1995, 60, 3680-3684.

8. For selected examples of see: (a) Sowa, T.; Ouchi, S. The Facile Synthesis of 5'-Nucleotides by the Selective Phosphorylation of a Primary Hydroxyl Group of Nucleosides with Phosphoryl Chloride. Bull. Chem. Soc. Jpn. 1975, 48, 2084-2090. (b) Murray, J. I.; Woscholski, R.; Spivey, A. C. Highly efficient and selective phosphorylation of amino acid derivatives and polyols catalysed by 2-aryl-4(dimethylamino)pyridine- $\mathrm{N}$-oxides $\quad-$ towards kinase-like reactivity. Chem. Commun. 2014, 50, 13608-13611. (c) Spicer, C. D.; Pujari-Palmer, M.; Autefage, H.; Insley, G.; Procter, P.; Engqvist, H.; Stevens, M. M. Synthesis of Phospho-Amino Acid Analogues as Tissue Adhesive Cement Additives. ACS Cent. Sci. 2020, 6, 226-231. (d) Redpath, P.; Ness, K. A.; Rousseau, J.; MacDonald, S. J. F.; Migaud, M. E. Facile access to new C-glycosides and C-glycoside scaffolds incorporating functionalized aromatic moieties. Carbohydr. Res. 2015, 402, 25-34.

9. For selected examples see: (a) Yamaguchi, H.; Ogura, F.; Otsubo, T.; Ikeura, Y. Phosphorylation with Pyrophosphoric Acid. Bull. Chem. Soc. Jpn. 1981, 54, 1891-1892. (b) Sakakura, A.; Katsukawa, M.; Ishihara, K. Selective Synthesis of Phosphate Monoesters by Dehydrative Condensation of Phosphoric Acid and Alcohols Promoted by Nucleophilic Bases. Org. Lett. 2005, 7, 1999-2002. (c) Sakakura A.; Katsukawa, M.; Ishihara, K. The Oxorhenium(VII)-Catalyzed Direct Condensation of Phosphoric Acid with Alcohol. Angew. Chem. Int. Ed. 2007, 46, 1423-1426.

10. For selected examples see: (a) Lira, L. M.; Vasilev, D.; Pilli R. A.; Wessjohann, L. A.; One-pot synthesis of organophosphate 
monoesters from alcohols. Tetrahedron Lett. 2013, 54, 16901692. (b) Dueymes, C.; Pirat, C.; Pascal, R. Facile synthesis of simple mono-alkyl phosphates from phosphoric acid and alcohol. Tetrahedron Lett. 2008, 49, 5300-5301. (c) Ramirez, F.; Marecek, J. F.; Yemul, S. S. Synthesis of Steroid Phosphates via Monomeric Metaphosphate. J. Org. Chem. 1983, 48, 1417-1420.

11. (a) Domon, K.; Puripat, M.; Fujiyoshi, K.; Hatanaka, M.; Kawashima, S. A.; Yamatsugu, K.; Kanai, M. Catalytic Chemoselective $O$-Phosphorylation of Alcohols. ACS Cent. Sci. 2020, 6, 283-292. (b) Fujiyoshi, K.; Kawashima, S. A.; Yamatsugu, K.; Kanai, M. A Single-Step Asymmetric Phosphodiester Synthesis from Alcohols with Phosphoenolpyruvate Phosphodiester. Synlett 2021, 32, 11351140

12. (a) Knouse, K. W.; deGruyter, J. N.; Schmidt, M. A.; Zheng, B.; Vantourout, J. C.; Kingston, C.; Mercer, S. E.; McDonald, I. M.; Olson, R. E.; Zhu, Y.; Hang, C.; Zhu, J.; Yuan, C.; Wang, Q.; Park. P.; Eastgate, M. D.; Baran, P. S. Unlocking P(V): Reagents for chiral phosphorothioate synthesis. Science 2018, 361, 1234-1238. (b) Maity, P.; Anandamurthy, A. S.; Shekarappa, V.; Vaidyanathan, R.; Zheng, B.; Zhu, J.; Schmidt, M. A.; Fox, R. J.; Knouse, K. W.; Vantourout, J. C.; Baran, P. S.; Eastgate, M. D. Synthesis of a Phosphorus Sulfur Incorporating Reagent for the Enantioselective Synthesis of Thiophosphates. Org. Synth. 2021, 98, 97-116.

13. Zheng, B.; Hang, C.; Zhu, J.; Purdum, G. E.; Sezen-Edmonds, M.; Treitler, D. S.; Yu, M.; Yuan, C.; Zhu, Y.; Freitag, A.; Guo, S.; Zhu, G.; Hritzko, B.; Paulson, J.; Shackman, J. G.; He, B. L.; Fu, W.; Chai Tai, H.; Ayers, S.; Park, H.; Eastgate, M. D.; Cohen, B.; Rogers, A.; Wang, Q.; Schmidt, M. A. P(III) vs $\mathrm{P}(\mathrm{V})$ : A P(V) Reagent for Thiophosphoramidate Linkages and Application to an Asymmetric Synthesis of a Cyclic Dinucleotide STING Agonist. J. Org. Chem. 2021, doi: 10.1021/acs.joc.1c01055.

14. Xu, D.; Rivas-Bascón, N.; Padial, N. M.; Knouse, K. W.; Zheng, B.; Vantourout, J. C.; Schmidt, M. A.; Easgate, M. D.; Baran, P. S. Enantiodivergent Formation of C-P Bonds: Synthesis of P-Chiral Phosphines and Methylphosphonate Oligonucleotides. J. Am. Chem. Soc. 2020, 142, 5785-5792.

15. Flood, D. T.; Knouse, K. W.; Vantourout J. C.; Kitamura, S.; Sanchez, B. B.; Sturgell, E. J.; Chen, J. S.; Wolan, D. W.; Baran, P. S.; Dawson, P. E. Synthetic Elaboration of Native DNA by RASS (SENDR). ACS Cent. Sci. 2020, 6, 1789-1799.

16. Vantourout, J. C.; Adusumalli, S. R.; Knouse, K. W.; Flood, D. T.; Ramirez, A.; Padial, N. M.; Istrate, A.; Maziarz, K.; deGruyter, J. N.; Merchant, R. R.; Qiao, J. X.; Schmidt, M. A.; Deery, M. J.; Eastgate, M. D.; Dawson, P. E.; Bernardes, G. J. L.; Baran, P. S. Serine-Selective Bioconjugation. J. Am. Chem. Soc. 2020, 142, 17236-17242.

17. He, C.; Chu, H.; Stratton, T. P.; Kossler, D.; Eberle, K. J.; Flood, D. T.; Baran, P. S. Total Synthesis of Tagetitoxin. J. Am. Chem. Soc. 2020, 142, 13683-13688.

18. Huang, Y.; Knouse, K. W.; Qiu, S.; Hao, W.; Padial, N. M.; Vantourout, J. C.; Zheng, B.; Mercer, S. E.; Lopez, J. O.; Narayan, R.; Olson, R. E.; Blackmond, D. G.; Eastgate, M. D.; Schmidt, M. A.; McDonald, I. M.; Baran, P. S. A P(V)-
Platform for Oligonucleotide Synthesis. ChemRxiv 2021, doi: 10.26434/chemrxiv.14403488.v1.

19. Lee, O. K.; Byon, Y. H.; Lee, B. S.; Hong, J. E.; Ko, J. S.; Cho, Y. K.; Lee. H. Method for preparing 3-aminopropane phosphoric acid. Patent no. US 5723645, 1996.

20. (a) Li, L. D.; Tang, W.; Liu, W. J.; Zhao, Z. B. Synthesis and Activity of the Photoaffinity-Labeled Functional Probe Based on Prenyl Side-Chain. Chin. J. Org. Chem. 2008, 28, 489-493. (b) Barker, R.; Olsen, K. W.; Shaper, J. H.; Hill, R. L. Agarose Derivatives of Uridine Diphosphate and $\mathrm{N}$-Acetylglucosamine for the Purification of Galactosyltransferase. J. Biol. Chem. 1972, 247, 7135-7147. (c) Kong, W. B.; Zhou, X. Y.; Yang, Y.; Xie, X. Y. A facile synthesis of $\varpi$-aminoalkyl ammonium hydrogen phosphates. Chin. Chem. Lett. 2012, 23, 923-926.

21. Singh, J.; Steck, N.; De, D.; Hofer, A.; Ripp, A.; Captain, I.; Keller, M.; Wender, P. A.; Bhandari, R.; Jessen, H. J. A Phosphoramidite Analogue of Cyclotriphosphate Enables Iterative Phosphorylations. Angew. Chem. Int. Ed. 2019, 58, 3928-3933.

22. (a) Lee, S.; Elphick, L. M.; Anderson, A. A.; Bonnac, L.; Child, E. S.; Mann, D. J.; Gouverneur, V. Synthesis and reactivity of novel $\gamma$-phosphate modified ATP analogues. Bioorg. Med. Chem. Lett. 2009, 19, 3804-3807. (b) Jayasekara, P. S.; Barrett, M. O.; Ball, C. B.; Ball, C. B.; Brown, K. A.; Kozma, E.; Costanzi, S.; Squarcialupi, L.; Balasubramanian, R.; Maruoka, H.; Jacobson, K. A. 4-Alkyloxyimino-cytosine nucleotides: tethering approaches to molecular probes for the $\mathrm{P}_{2} \mathrm{Y}_{6}$ receptor. Med. Chem. Commun. 2013, 4, 1156-1165.

23. Fölsch, G.; Österberg, R.; The Apparent Ionization Constants. of Some $O$-Phosphorylated Peptides and Related Compounds. J. Biol. Chem. 1959, 234, 2298-2303.

24. (a) Schott, H.; Ludwig, P. S.; Immelmann, A.; Schwendener, R. A. Synthesis and in vitro anti-HIV activities of amphiphilic heterodinucleoside phosphate derivatives containing 2',3'dideoxynucleosides ddC, AZT and ddI. Eur. J. Med. Chem. 1999, 34, 343-352. (b) Thomson, W.; Nicholls, D.; Irwin, W. J.; Al-Mushadani, J. S.; Freeman, S.; Karpas, A.; Petrik, J.; Mahmood, N.; Hay, A. J. Synthesis, bioactivation and antiHIV activity of the bis(4-acyloxybenzyl) and mono(4acyloxybenzyl) esters of the 5'-monophosphate of AZT. $J$. Chem. Soc., Perkin Trans. 1 1993, 1239-1245. (c) Rachwalak, M., Rozniewska, M.; Golebiewska, J.; Jakubowski, T.; Sobkowski, M.; Romanowska, J. A practical synthesi of nucleoside 5'-diphosphates from nucleoside 5' $-H$-phosphonate monoesters. Synth. Commun. 2020, 50, 3836-3844. (d) Roesler, G.; Jastorff, B. 3'-modified nucleotides: Substrate recognition by phosphohydrolases. Bioorg. Chem. 1978, 7, 3545.

25. McGuigan, C.; Nickson, C.; Petrik, J.; Karpas, A.; Phosphate derivatives of AZT display enchanced selectivity of action against HIV1 by comparision to the parent nucleoside. FEBS Lett. 1992, 310, 171-174.

26. Watanabe, Y.; Nakamura, T.; Mitsumoto, H. Protection of phosphate with the 9-fluorenylmethyl group. Synthesis of Unsaturated-acyl Phosphatidylinositol 4,5-Bisphosphate. Tetrahedron Lett. 1997, 38, 7407-7410. 
TOC Graphic:

Mild, Chemoselective Phosphorylation of Alcohols Using a -Reagent

[building blocks]

[drugs]

[biomolecules]

[scalable] [mild conditions] [one-pot] $\left[1^{\circ}, 2^{\circ}\right.$ and phenols]

[highly chemoselective] [operationally simple] 